\title{
'|||||||||||||||||||||||||||||||||||||||||||||||||||||||||||||||||||.
}

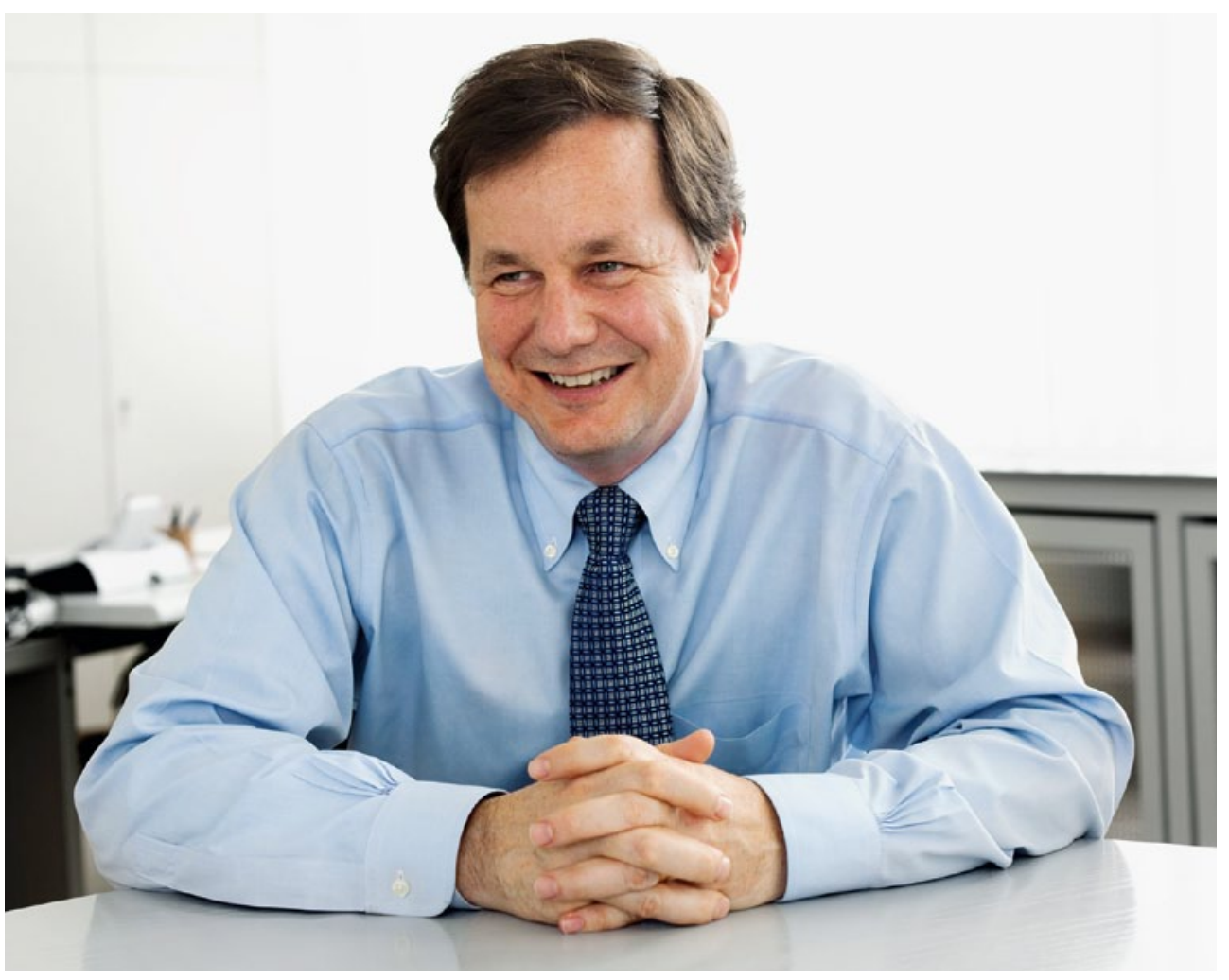

MICHAEL ABLESON

Vorstandsmitglied für Forschung und Entwicklung, Opel, und GM Europe Vice President Engineering

\section{EINE RECHNUNG, DIE AUFGEHT}

Die Emissionsvorgaben der EU für 2020 werfen ihre Schatten voraus. In knapp sieben Jahren sollen Pkw durchschnittlich höchstens $95 \mathrm{~g} \mathrm{CO}_{2}$ pro Kilometer ausstoßen. Neue Anforderungen wie die Partikelanzahlbegrenzung bei Euro 6c und RDE (Real Driving Emissions) stellen dabei verschärfte Randbedingungen dar. Die Entwicklung neuer Motoren zum Erreichen dieses Ziels läuft deshalb bereits auf Hochtouren. Schlüsselbegriffe sind hier Right- beziehungsweise Downsizing, Direkteinspritzung, Reibungsreduzierung und optimiertes Thermomanagement. Hinzu kommen weiterentwickelte, reibungsreduzierte Getriebe mit optimaler Gangübersetzung, die ebenso helfen, den Kraftstoffverbrauch zu senken, wie Gewichtseinsparungen und aerodynamisches Design auf der Fahrzeugseite.

Dies alles lässt sich durch intensive Forschungs- und Entwicklungsarbeit erreichen, doch für uns als Automobilhersteller ist ein weiterer Punkt besonders wichtig, wollen wir Erfolg bei unseren Kunden haben: Auch mit strengen Verbrauchs- und Emissionsvorgaben muss Autofahren noch Spaß machen - und ein Neuwagen gleichzeitig für den Käufer bezahlbar bleiben. Die Frage lautet also nicht „ob“, sondern „wie“ wir dies erreichen können. Es reichen nicht hochoptimierte Motoren und Getriebe auf der einen sowie die passenden Fahrzeuge auf der anderen Seite - einen entscheidenden Beitrag wird die Integration der Antriebe in die jeweiligen Fahrzeuge leisten, sodass die Leistung und das Fahrerlebnis die Kunden genauso überzeugen wie der Preis.

Die passenden Autos für die kommenden Jahre stehen bei Opel bereits in den Startlöchern. In einer einzigartigen Produktoffensive bringen wir von 2012 bis 2016 insgesamt 23 neue Modelle auf den Markt - ein Teil unseres Zukunftsplans „Drive! 2022“, der Opel langfristig zurück auf die Erfolgsspur führen wird. Zugleich bringen wir unsere Antriebspalette mit neuen Familien mittelgroßer Otto- und Dieselmotoren sowie kleinen Ottomotoren mit Vollgas auf Vordermann.

Den Anfang in der Reihe der völlig neu konstruierten Opel-Vierzylinder-Triebwerke mit Benzin-Direkteinspritzung (SIDI $=$ Spark Ignition Direct Injection) macht der 1.6 SIDI Ecotec Turbo, der ab diesem Frühjahr in diversen Modellen Premiere feiert. Mit einem komplett neuen Vierzylinder-Turbodiesel setzen wir die Modernisierung des Motorenprogramms fort. Der 1.6 CDTI Ecotec mit Aluminiumblock setzt Maßstäbe bei Laufruhe, Kraftentfaltung und Umweltverträglichkeit. Damit erfüllt Opel erstmals mit einem Diesel die verschärften Regularien der künftigen Euro-6-Schadstoffklasse - gute Aussichten also, um auch unter verschärften Umweltauflagen in Zukunft mit Spaß durchstarten zu können. 